\title{
Editorial
}

\section{Bulking up the hippocampus in schizophrenia: a role for $5-\mathrm{HT}_{1 \mathrm{~A}}$ agonists?}

\author{
Sophia Frangou
}

\section{Summary}

The volume of the hippocampus is reduced in patients with schizophrenia, and this deficit tends to become more pronounced with chronicity. Newer antipsychotics may protect against the progressive reductions in hippocampal volume while preliminary data offer hope that specific antipsychotics may act to reverse it.

\section{Declaration of interest}

None.

\section{Copyright and usage}

(c) The Royal College of Psychiatrists 2016. This is an open access article distributed under the terms of the Creative commons Non-Commercial, No Derivatives (CC BY-NC-ND) licence.
Sophia Frangou is Professor of Psychiatry at the Icahn School of Medicine at Mount sinai where she conducts research on brain imaging in psychotic disorders.

Schizophrenia is a chronic debilitating disorder whose aetiology and pathophysiology are yet to be fully characterised. Neuroimaging studies have had a transformative influence on our understanding of schizophrenia and have firmly established the presence of brain pathology in individuals suffering from this disorder. Brain structural alterations are present early in the disease trajectory ${ }^{1}$ and continue to unfold for years after disease onset. $^{2,3}$ Brain volume reductions in patients proceed at a mean annual rate of $0.69 \%$ (compared with $0.49 \%$ in healthy controls) and show significant inter-individual variability; ${ }^{2}$ patients with poor outcomes show more pronounced reductions compared with those with better outcomes. ${ }^{2,3}$

For the majority of patients, these progressive brain changes occur in the context of ongoing treatment with antipsychotic medications. Antipsychotic medications are effective in reducing the severity and length of psychotic episodes and the risk of relapse. ${ }^{4}$ There is however increasing and compelling evidence that antipsychotics impact on brain structure and that the magnitude and direction of this effect depends on antipsychotic class. ${ }^{1-3,5-9}$ Firstgeneration antipsychotics (FGAs) include agents such as haloperidol and chlorpromazine, which show high affinity for and act as full antagonists at dopamine $\mathrm{D}_{2}$ receptors. ${ }^{4}$ Second-generation antipsychotics (SGAs) include amisulpride, asenapine, clozapine, iloperidone, lurasidone, olanzapine, paliperidone, risperidone, quetiapine and ziprasidone. In addition to $\mathrm{D}_{2}$ receptor antagonism, SGAs interact with serotonin (5-hydroxytryptamine; 5-HT), histamine and adrenergic receptors. ${ }^{4}$ Aripiprazole, also referred as a thirdgeneration antipsychotic, acts as a $\mathrm{D}_{2}, 5 \mathrm{HT}_{1 \mathrm{~A}}$ and $5 \mathrm{HT}_{7}$ receptor agonist and as a $\mathrm{D}_{1}, 5 \mathrm{HT}_{2 \mathrm{~A}}$ and $5 \mathrm{HT}_{6}$ receptor antagonist. ${ }^{4}$

In a seminal study published a decade ago, Lieberman and colleagues ${ }^{5}$ provided evidence for a differential effect of antipsychotic class on grey matter volume in first-episode patients with schizophrenia. Patients were treated in a randomised, controlled double-blind design either with haloperidol or olanzapine. Magnetic resonance imaging (MRI) data were acquired at baseline and then at weeks 12, 24, 52 and 104. Decreased grey matter volume was seen in the haloperidol-treated but not the olanzapine-treated group. A subsequent analysis of the same MRI data used cortical pattern matching to examine medication-related differences in the longitudinal evolution of grey matter density changes. ${ }^{6}$ Over the follow-up period, cortical grey matter density loss in the haloperidol-treated group spread from parietal to frontal regions while this pattern was much attenuated in the olanzapine-treated group.

Several studies have since compared the effect of FGAs and SGAs on global and regional grey matter volume in schizophrenia. A recent quantitative meta-analysis included 18 longitudinal studies of whole brain, frontal, temporal, and parietal grey matter involving 1155 patients with schizophrenia and 911 healthy comparison individuals. ${ }^{7}$ A statistically significant progressive decrease in global and regional grey matter volume was found in the subgroup of studies that examined patients treated with FGAs or combinations of FGAs and SGAs. For global grey matter, the degree of change correlated with the mean daily FGA dose. In the subgroup of studies that included patients treated only with SGAs, no progressive volumetric decline was observed and there was a numerical, but not statistically significant, increase in frontal and temporal grey matter. In this subgroup, the higher the SGA mean daily dose during the follow-up, the lower the reduction in grey matter volume. The effect size of the reported changes ranged from small to moderate for all the SGAs examined.

In contrast to global or lobar measures of grey matter, the relationship of antipsychotic treatment to hippocampal volume is less clear. Bilateral hippocampal volume reduction has been consistently reported in schizophrenia. ${ }^{1,8}$ Initially, it may be localised within specific hippocampal subfields, particularly CA1, but it becomes more pronounced with chronicity, independent of antipsychotic exposure. ${ }^{8}$ The largest meta-analysis of relevant case-control MRI studies found that reductions in hippocampal volume were comparable between medication-naïve schizophrenia patients (mean weighted effect size: 0.43 ) and those on medication (mean weighted effect size: 0.52 ). ${ }^{1}$ However, over a 2-year-period, the slope of change in hippocampal volume and shape seems to be attenuated in first-episode patients with schizophrenia randomised to treatment with olanzapine compared with those randomised to treatment with haloperidol. ${ }^{9}$ Bodnar and colleagues contribute further to the evidence on the effect of different antipsychotic classes on hippocampal volume in their recent study. ${ }^{10}$ They recruited patients under the care of the Prevention and Early Intervention Program for Psychoses based at the Douglas Mental Health University Institute in Montreal, Canada. 
The study sample comprised 88 patients with first-episode psychosis, treated between January 2004 and June 2014, and 46 healthy comparison individuals. Just over a quarter of the initial patient sample was excluded based on a variety of clinical and technical reasons. The remaining 62 patients were divided according to medication status into four groups: those that refused medication $(n=13)$ and those who had been treated for a minimum of 6 months with risperidone/paliperidone $(n=24)$, olanzapine $(n=12)$ or aripiprazole $(n=13)$ as monotherapy. The different treatment groups were comparable in terms of demographic characteristics, clinical features and clinical improvement. All participants had two brain MRI scans with an average interscan interval of 1 year. Measures of hippocampal and total intracranial volume were extracted from the two MRI data-sets to estimate change over time. Mean within-group changes in hippocampal volumes were negligible for all groups with the exception of patients that had been mostly treated with aripiprazole. This group showed a mean within-group increase in hippocampal volume of $1-2 \%$. Given that studies with small sample sizes may overestimate the magnitude of an association, interpretation of the results must proceed with caution. Moreover, the mechanisms underlying the hippocampal volume increases in aripiprazoletreated patients cannot be inferred from the available imaging data. The clinical relevance of this finding is also unclear as treatment with aripiprazole did not lead to greater symptomatic improvement. Although speculative, the agonist activity of aripiprazole at the $5-\mathrm{HT}_{1 \mathrm{~A}}$ receptor may be relevant to its differential effect on hippocampal volume compared with other antipsychotic agents examined by Bodnar and colleagues. The $5-\mathrm{HT}_{1 \mathrm{~A}}$ receptors are major inhibitory G-protein-coupled receptor subtypes found on pre- and post-synaptic neurons throughout the brain. They are highly expressed in brain regions implicated in affect regulation and memory processing, including the hippocampus, particularly in the CA1 region, the amygdala and in the frontal, cingulate and entorhinal cortices. ${ }^{11} 5-\mathrm{HT}_{1 \mathrm{~A}}$ receptors influence dopaminergic, cholinergic, glutamatergic and GABAergic functions. In this context, $5-\mathrm{HT}_{1 \mathrm{~A}}$ receptor agonists have been considered as potentially pro-cognitive on the basis of preclinical evidence that they modulate the release of cortical and hippocampal dopamine and acetylcholine. ${ }^{11}$ Aripiprazole shares this $5-\mathrm{HT}_{1 \mathrm{~A}}$ agonist property with other psychotropic drugs notably asenapine, buspirone, clozapine, lurasidone and ziprasidone. ${ }^{4}$ Despite some positive results, the evidence for a reliable pro-cognitive effect of 5- $\mathrm{HT}_{1 \mathrm{~A}}$ agonists in patients with schizophrenia is far from robust. ${ }^{11}$ Although the effect of psychotropic drugs is traditionally considered in terms of their neurotransmitter action, their influence on brain structure and function may involve other mechanisms. Of relevance to the findings by Bodnar and colleagues, preclinical studies suggest that chronic activation of post-synaptic $5-\mathrm{HT}_{1 \mathrm{~A}}$ receptors may encourage neurite growth in the hippocampus and the up-regulation of neurotrophins such as brain-derived neurotrophic factor; ${ }^{12}$ both of these mechanisms could potentially account for the observed increase in hippocampal volume in patients mostly treated with aripiprazole. The complexity of the interactions between treatment, disease process and brain structure and function in schizophrenia underscores the importance of reproducible findings in large independent samples in order to determine whether different antipsychotics have distinct effects and, if that is the case, to characterise potential mechanisms and clinical implications.

Sophia Frangou, MD, PhD, FRCPsych, Department of Psychiatry, Icahn School of Medicine at Mount Sinai, New York, NY, USA

Correspondence: Sophia Frangou, Icahn School of Medicine at Mount Sinai, 1425 Madison Avenue, New York, NY 10029, USA. Email: sophia.frangou@mssm.edu

First received 15 May 2016, final revision 27 June 2016, accepted 28 Jun 2016

\section{References}

1 Haijma SV, Van Haren N, Cahn W, Koolschijn PC, Hulshoff Pol HE, Kahn RS. Brain volumes in schizophrenia: a meta-analysis in over 18000 subjects. Schizophr Bull 2013; 39: 1129-38.

2 Veijola J, Guo JY, Moilanen JS, Jääskeläinen $E$, Miettunen J, Kyllönen $M$, et al. Longitudinal changes in total brain volume in schizophrenia: relation to symptom severity, cognition and antipsychotic medication. PLOS One 2014; 9: e101689.

3 van Haren NE, Hulshoff Pol HE, Schnack HG, Cahn W, Mandl RC, Collins DL, et al. Focal gray matter changes in schizophrenia across the course of the illness: a 5-year follow-up study. Neuropsychopharmacology 2007; 32: 2057-66.

4 Miyamoto S, Miyake N, Jarskog LF, Fleischhacker WW, Lieberman JA. Pharmacological treatment of schizophrenia: a critical review of the pharmacology and clinical effects of current and future therapeutic agents. Mol Psychiatry 2012; 17: 1206-27.

5 Lieberman JA, Tollefson GD, Charles C, Zipursky R, Sharma T, Kahn RS, et al. Antipsychotic drug effects on brain morphology in first-episode psychosis. Arch Gen Psychiatry 2005; 62: 361-70.

6 Thompson PM, Bartzokis G, Hayashi KM, Klunder AD, Lu PH, Edwards N, et al. Time-lapse mapping of cortical changes in schizophrenia with different treatments. Cereb Cortex 2009; 19: 1107-23.

7 Vita A, De Peri L, Deste G, Barlati S, Sacchetti E. The effect of antipsychotic treatment on cortical gray matter changes in schizophrenia: does the class matter? A meta-analysis and meta-regression of longitudinal magnetic resonance imaging studies. Biol Psychiatry 2015; 78: 403-12.

8 Ho NF, Iglesias JE, Sum MY, Kuswanto CN, Sitoh YY, De Souza J, et al. Progression from selective to general involvement of hippocampal subfields in schizophrenia. Mol Psychiatry 23 Feb 2016. (http://dx.doi.org/10.1038/mp.2016.4)

9 Mamah D, Harms MP, Barch D, Styner M, Lieberman JA, Wang L. Hippocampal shape and volume changes with antipsychotics in early stage psychotic illness. Front Psychiatry 2012; 3: 96. (http://dx.doi.org/10.3389/fpsyt.2012.00096).

10 Bodnar M, Malla AK, Makowski C, Chakravarty MM, Joober R, Lepage M. The effect of second-generation antipsychotics on hippocampal volume in first episode of psychosis: Iongitudinal study. Br J Psychiatry Open 2016; 2: 139-46. (http://dx.doi.org/10.1192/bjpo.bp.115.002444).

11 Meltzer HY, Sumiyoshi T. Does stimulation of $5-\mathrm{HT}(1 \mathrm{~A})$ receptors improve cognition in schizophrenia? Behav Brain Res 2008; 195: 98-102.

12 McCreary AC, Newman-Tancredi A. Serotonin 5-HT1A receptors and antipsychotics - an update in light of new concepts and drugs. Curr Pharm Des 2015; 21 3725-31. 